\title{
RTTOV-gb v1.0 - updates on sensors, absorption models, uncertainty, and availability
}

\author{
Domenico Cimini $^{1,2}$, James Hocking ${ }^{3}$, Francesco De Angelis ${ }^{2}$, Angela Cersosimo ${ }^{1}$, Francesco Di Paola ${ }^{1}$, \\ Donatello Gallucci $^{1}$, Sabrina Gentile ${ }^{1}$, Edoardo Geraldi ${ }^{1}$, Salvatore Larosa ${ }^{1}$, Saverio Nilo ${ }^{1}$, Filomena Romano ${ }^{1}$, \\ Elisabetta Ricciardelli ${ }^{1}$, Ermann Ripepi ${ }^{1}$, Mariassunta Viggiano ${ }^{1}$, Lorenzo Luini ${ }^{4}$, Carlo Riva ${ }^{4}$, Frank S. Marzano ${ }^{5,2}$, \\ Pauline Martinet $^{6}$, Yun Young Song ${ }^{7}$, Myoung Hwan Ahn ${ }^{7}$, and Philip W. Rosenkranz ${ }^{8}$ \\ ${ }^{1}$ National Research Council of Italy, Institute of Methodologies for Environmental Analysis, Potenza, 85050, Italy \\ ${ }^{2}$ Center of Excellence CETEMPS, University of L'Aquila, L'Aquila, 67100, Italy \\ ${ }^{3}$ Met Office, Exeter, UK \\ ${ }^{4}$ DEIB - Politecnico di Milano, IEIIT - CNR, Milan, Italy \\ ${ }^{5}$ University of Rome La Sapienza, Rome, Italy \\ ${ }^{6}$ CNRM, Université de Toulouse, Météo-France, CNRS, Toulouse, France \\ ${ }^{7}$ School of Engineering, Ewha Womans University, Seoul, South Korea \\ ${ }^{8}$ Massachusetts Institute of Technology, Cambridge, MA 02139, USA
}

Correspondence: Domenico Cimini (domenico.cimini@imaa.cnr.it)

Received: 14 November 2018 - Discussion started: 21 January 2019

Revised: 30 March 2019 - Accepted: 16 April 2019 - Published: 9 May 2019

\begin{abstract}
This paper describes the first official release (v1.0) of RTTOV-gb. RTTOV-gb is a FORTRAN 90 code developed by adapting the atmospheric radiative transfer code RTTOV, focused on satellite-observing geometry, to the groundbased observing geometry. RTTOV-gb is designed to simulate ground-based upward-looking microwave radiometer (MWR) observations of atmospheric downwelling natural radiation in the frequency range from 22 to $150 \mathrm{GHz}$. Given an atmospheric profile of temperature, water vapor, and, optionally, cloud liquid water content, and together with a viewing geometry, RTTOV-gb computes downwelling radiances and brightness temperatures leaving the bottom of the atmosphere in each of the channels of the sensor being simulated. In addition, it provides the sensitivity of observations to the atmospheric thermodynamical state, i.e., the Jacobians. Therefore, RTTOV-gb represents the forward model needed to assimilate ground-based MWR data into numerical weather prediction models, which is currently pursued internationally by several weather services. RTTOV-gb is fully described in a previous paper (De Angelis et al., 2016), while several updates are described here. In particular, two new MWR types and a new parameterization for the atmospheric absorption model have been introduced since the first
\end{abstract}

paper. In addition, estimates of the uncertainty associated with the absorption model and with the fast parameterization are given here. Brightness temperatures $\left(\boldsymbol{T}_{\mathrm{B}}\right)$ computed with RTTOV-gb v1.0 from radiosonde profiles have been compared with ground-based MWR observations in six channels $(23.8,31.4,72.5,82.5,90.0$, and $150.0 \mathrm{GHz})$. The comparison shows statistics within the expected accuracy. RTTOV$\mathrm{gb}$ is now available to licensed users free of charge from the Numerical Weather Prediction Satellite Application Facility (NWP SAF) website, after registration. Coefficients for four MWR instrument types and two absorption model parameterizations are also freely available from the RTTOV-gb support website.

\section{Introduction}

RTTOV-gb is a fast radiative transfer code, designed to simulate ground-based upward-looking microwave radiometer (MWR) observations of atmospheric downwelling natural radiation (i.e., radiances). RTTOV-gb consists of the FORTRAN 90 code described by De Angelis et al. (2016), developed by adapting version 11.2 of RTTOV, the Radia- 
tive Transfer for the TIROS Operational Vertical Sounder (TOVS), which is designed to simulate the satellite observation perspective only. From its first implementation (Eyre, 1991) through to its current version (Saunders et al., 2018), RTTOV simulates radiances from spaceborne passive sensors and also computes the Jacobians, i.e., the gradient of the radiances with respect to the atmospheric state vector. RTTOV is widely used by many national and international meteorological services for assimilating down-looking observations from visible, infrared, and microwave radiometers, spectrometers, and interferometers aboard satellite platforms. For this reason, RTTOV is maintained and continuously developed by the Numerical Weather Prediction (NWP) Satellite Application Facility (SAF) of the European Organization for the Exploitation of Meteorological Satellites (EUMETSAT). However, satellite passive observations are known to lack accuracy and resolution in the planetary boundary layer (PBL), leaving a so-called observational gap between the surface and upper troposphere (National Research Council, 2008). Therefore, in the last decade there has been increasing interest in ground-based sensors that could help bridge the PBL observational gap (Illingworth et al., 2015, 2019), including ground-based microwave radiometers (MWR). Ground-based MWR observations are also widely used for radio propagation studies and the characterization of atmospheric attenuation for telecommunication channels (Riva et al., 2014).

Data assimilation of MWR observations into NWP models may be particularly important in forecasting weather and atmospheric attenuation. In order to assimilate groundbased radiometric observations, namely brightness temperatures $\left(\boldsymbol{T}_{\mathrm{B}}\right)$, a fast radiative transfer forward model is needed. This model allows rapid simulations of $\boldsymbol{T}_{\mathrm{B}}$ at selected radiometer channels based on the NWP model state vector, i.e., atmospheric temperature and humidity profiles, similar to what RTTOV does for satellite sensors. Therefore, in the framework of the COST (European Cooperation in Science and Technology) Actions EG-CLIMET (European GroundBased Observations of Essential Variables for Climate and Operational Meteorology) and TOPROF (Towards operational ground based profiling with ceilometers, doppler lidars and microwave radiometers for improving weather), there have been continuous activities to develop a ground-based version of RTTOV: RTTOV-gb (De Angelis et al., 2016). RTTOV-gb is a one-dimensional radiative transfer model: for any given location, it takes vertical profiles of atmospheric temperature, water vapor, and cloud liquid water specified on an arbitrary set of pressure levels, and from them it simulates $\boldsymbol{T}_{\mathrm{B}}$ as well as the Jacobians (i.e., the sensitivity of $\boldsymbol{T}_{\mathrm{B}}$ to atmospheric thermodynamical profiles) corresponding to ground-based upward-looking microwave radiometers. The radiative transfer extends to the top of the atmosphere, and it includes an extra-terrestrial contribution, i.e., the cosmic background radiation. The availability of RTTOV-gb is fostering wider use of MWR observations in NWP models, as demonstrated by the current use at some of the most relevant meteorological services in Europe as well as outside, such as Météo-France, the German Meteorological Service (Deutscher Wetterdienst, DWD), and the Korean Meteorological Administration (KMA).

This paper introduces several updates of RTTOV-gb since its first development (De Angelis et al., 2016). In Sect. 2 we introduce a new absorption model parameterization and two new sensors that have been added among the setting options. Section 3 presents the evaluation of RTTOV-gb against the reference line-by-line radiative transfer model and real radiometric ground-based observations. Section 4 summarizes the findings while the code and data availability section provides instructions for code and data access and use.

\section{RTTOV-gb updates}

\subsection{New sensors}

Similar to RTTOV, RTTOV-gb was designed to simulate observations and Jacobians for a suite of instruments, in this case ground-based instead of satellite-borne sensors. While introducing RTTOV-gb, De Angelis et al. (2016) presented results for two sensors, among the most common ground-based MWRs worldwide: the Humidity And Temperature PROfiler (HATPRO), manufactured by RPG, and the MP3000A, manufactured by Radiometrics. In the current version (v1.0), two more sensors have been added to the suite: the microwave temperature radiometer TEMPERA (Stähli et al., 2013; Navas-Guzmán et al., 2017) and the liquid water path (LWP) K-to-W-band radiometer (LWP_K2W). Note that LWP_K2W is a virtual instrument which includes all the channels offered by the LWP family of ground-based radiometers (LWP, LWP-U90, LWP-U72-82, LWP-U150, LWP-90-150) manufactured by RPG (https://www.radiometer-physics.de/products/ microwave-remote-sensing-instruments/radiometers/ lwp-radiometers/, last access: 14 November 2018).

The RTTOV-gb optical depth calculation is a parameterization which requires precomputed coefficients. These coefficients are specific to each instrument and are stored in coefficient files (see also Sect. 2.2). Every time a new sensor is added to the sensor suite, a dedicated coefficient file must be generated. The coefficient file contains the regression coefficients to estimate the optical depth for each atmospheric layer and each sensor channel from the thermodynamical properties of the layer through a set of predictors. The predictors are derived from the input state vector profile and depend on the elevation angle $\theta$ and pressure $P$, temperature $T$, and specific humidity $Q$ at the considered and surrounding levels. The regression coefficients are trained on a set of diverse profiles which covers the atmospheric conditions of different climate zones. Pressure levels and regression limits for $T$ and $Q$ are reported in Table 1 . The coeffi- 
cients are based on a set of 101 pressure levels specifically created for RTTOV-gb which are denser in the lower atmosphere than the RTTOV coefficient levels usually used for spaceborne sensors.

The list of currently supported sensors with their channel frequencies is given in Table 2. Other sensors are planned for future updates, e.g., those operating at $183 \mathrm{GHz}$ for low water vapor and cloud liquid water retrievals (Cimini et al., 2007).

\subsection{Absorption model}

Similar to RTTOV, RTTOV-gb is a parameterized atmospheric radiative transfer code. In the microwave region and for clear-sky conditions, the parameterization only affects the atmospheric gas absorption. This means that the optical depth of each layer is only due to absorption by atmospheric gases (mainly oxygen, water vapor, and nitrogen). The parameterization consists of the fact that the layer optical depth is not computed from a complex line-by-line (LBL) absorption model (Clough et al., 2005) but rather from a simplified parameterized model. The simplified model consists of a linear regression, which relates the layer optical depth to predictors derived from the layer atmospheric thermodynamical properties (i.e., pressure, temperature, and humidity). The regression coefficients are computed off-line from a diverse training dataset of atmospheric thermodynamical profiles and corresponding optical depths computed with an LBL model. Thus, RTTOV-gb provides a fast parameterization of the LBL model adopted for the training of the regression coefficients. For the microwave frequency range (10-200 GHz), the regression coefficients of RTTOV are trained using the AMSUTRAN LBL model developed at the Met Office (Turner et al., 2019), which is based on the millimeter-wave propagation model (MPM) introduced by Liebe (1989), with some modifications following Tretyakov et al. (2005), Liljegren et al. (2005), and Payne et al. (2008) (Saunders et al., 2017). Conversely, RTTOV$\mathrm{gb}$ was trained using a later version of MPM, described by Rosenkranz (1998, hereafter R98), which is probably the most used among the ground-based microwave radiometry community. This model is continuously revised and freely available (Rosenkranz, 2017, hereafter R17), and its uncertainty has been carefully investigated (Cimini et al., 2018). Therefore, RTTOV-gb has been trained using the R17 model also (version of 17 May 2017 available at http://cetemps. aquila.infn.it/mwrnet/lblmrt_ns.html, last access: 14 November 2018). Coefficients for both the R98 and R17 models are now available within RTTOV-gb v1.0. Extending the results in Cimini et al. (2018) from 60 to $150 \mathrm{GHz}$, Fig. 1 shows clear-sky zenith downwelling $\boldsymbol{T}_{\mathrm{B}}$ computed with the R17 model and the difference between $\boldsymbol{T}_{\mathrm{B}}$ computed with the two model versions for six reference atmosphere climatology conditions. The difference spans -2 to $+3 \mathrm{~K}$ in the con-
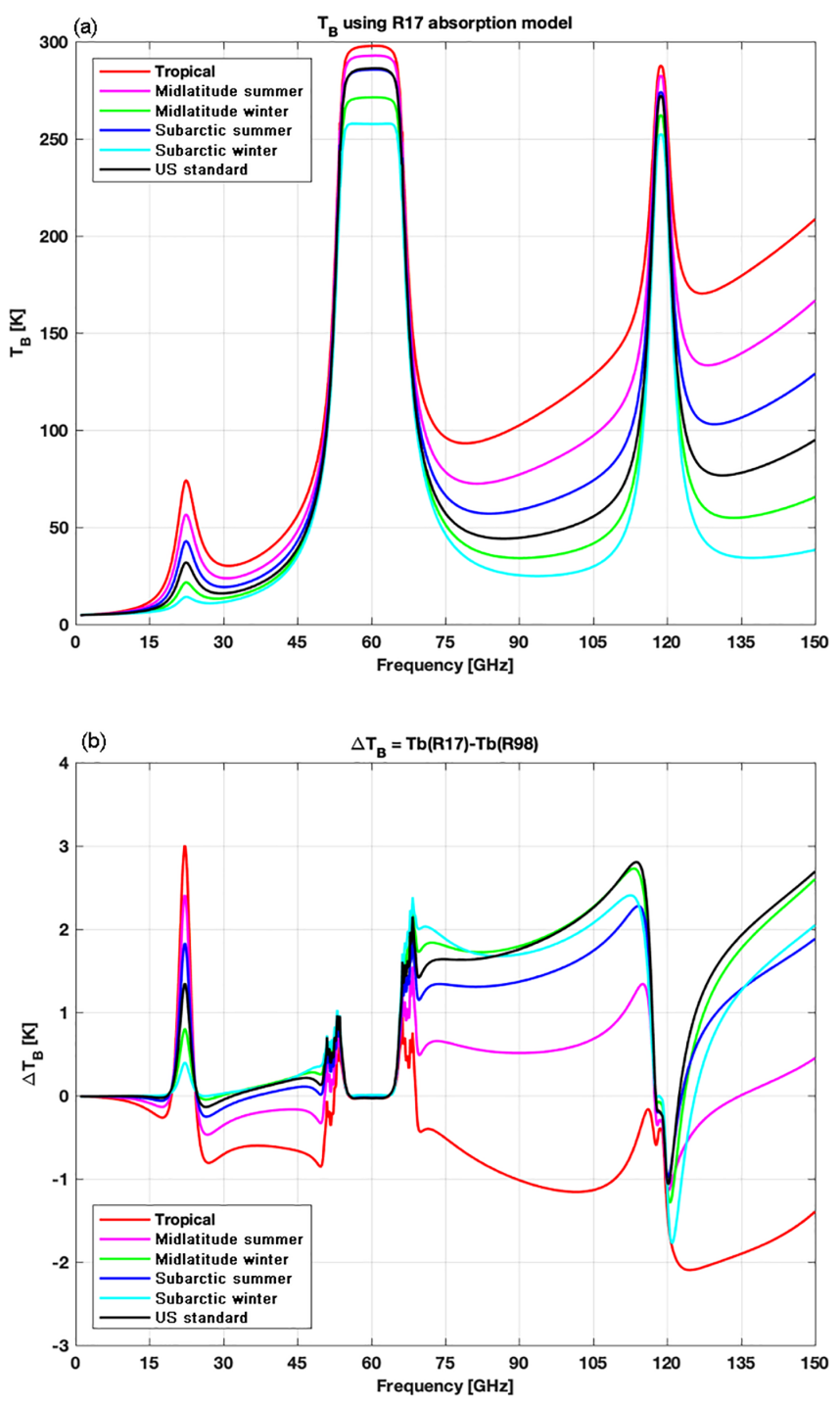

Figure 1. (a) Zenith downwelling $\boldsymbol{T}_{\mathrm{B}}$ computed using six reference atmosphere climatology conditions with the R17 model. (b) Difference between $\boldsymbol{T}_{\mathrm{B}}$ computed with the current and reference versions (R17 minus R98) for the six atmosphere climatology conditions. This figure is similar to Fig. 1 in Cimini et al. (2018), although $\boldsymbol{T}_{\mathrm{B}}$ were recomputed to cover a wider frequency range.

sidered frequency range, and thus it is not negligible for the sensors currently available for RTTOV-gb v1.0.

As mentioned, Cimini et al. (2018) investigated the uncertainty of $\boldsymbol{T}_{\mathrm{B}}$ computed with the R17 model due to the laboratory uncertainty of the adopted spectroscopic parameters. Through a sensitivity test, they identified 111 parameters ( 6 for water vapor and 105 for oxygen), whose contribution to the total uncertainty was dominant with respect to others. For these 111 parameters, Cimini et al. (2018) estimated the full uncertainty covariance matrix $(\operatorname{Cov}(p))$, from which the $\boldsymbol{T}_{\mathrm{B}}$ uncertainty covariance matrix $\left(\operatorname{Cov}\left(\boldsymbol{T}_{\mathrm{B}}\right)\right)$ and the square root of its diagonal terms $\left(\boldsymbol{\sigma}\left(\boldsymbol{T}_{\mathrm{B}}\right)\right)$ were computed. $\boldsymbol{\sigma}\left(\boldsymbol{T}_{\mathrm{B}}\right)$ rep- 
Table 1. A selection of the 101 pressure levels adopted for RTTOV-gb (De Angelis et al., 2016). The table also reports the limits for temperature $(T)$ and specific humidity $(Q)$ at each level representing the range of values used when training the regression coefficients. Note that $Q$ is in part per million in volume over dry air. The full matrix is provided as a Supplement to this paper and freely available online (http://cetemps.aquila.infn.it/mwrnet/main_files/DAT/RTTOVgb_101_pressure_levels_and_regression_limits.xlsx, last access: 14 November 2018).

\begin{tabular}{lrrrrr}
\hline $\begin{array}{l}\text { Level } \\
(\text { no. })\end{array}$ & $\begin{array}{r}\text { Pressure } \\
(1 e 3 \mathrm{hPa})\end{array}$ & $\begin{array}{r}\text { Minimum } T \\
(\mathrm{~K})\end{array}$ & $\begin{array}{r}\text { Maximum } T \\
(\mathrm{~K})\end{array}$ & $\begin{array}{r}\text { Minimum } Q \\
(\mathrm{ppmv})\end{array}$ & $\begin{array}{r}\text { Maximum } Q \\
(\mathrm{ppmv})\end{array}$ \\
\hline 1 & 0.0000 & 143.65 & 245.95 & $9.1330 \mathrm{E}-01$ & $5.2410 \mathrm{E}+00$ \\
11 & 0.0379 & 162.77 & 279.05 & $1.3280 \mathrm{E}+00$ & $6.0170 \mathrm{E}+00$ \\
21 & 0.1349 & 169.71 & 259.26 & $1.2860 \mathrm{E}-02$ & $1.0250 \mathrm{E}+02$ \\
31 & 0.2700 & 182.27 & 278.60 & $1.2860 \mathrm{E}-02$ & $4.5660 \mathrm{E}+03$ \\
41 & 0.4251 & 195.91 & 303.26 & $2.3870 \mathrm{E}+00$ & $1.6690 \mathrm{E}+04$ \\
51 & 0.5841 & 196.73 & 315.57 & $4.8630 \mathrm{E}+00$ & $2.8090 \mathrm{E}+04$ \\
61 & 0.7336 & 189.96 & 332.20 & $8.8570 \mathrm{E}+00$ & $3.7010 \mathrm{E}+04$ \\
71 & 0.8624 & 189.96 & 342.43 & $7.5350 \mathrm{E}+00$ & $4.4160 \mathrm{E}+04$ \\
81 & 0.9618 & 189.96 & 349.92 & $6.7550 \mathrm{E}+00$ & $5.1280 \mathrm{E}+04$ \\
91 & 1.0256 & 189.96 & 350.08 & $6.3350 \mathrm{E}+00$ & $4.7540 \mathrm{E}+04$ \\
101 & 1.0500 & 189.96 & 350.08 & $6.1880 \mathrm{E}+00$ & $4.7640 \mathrm{E}+04$ \\
\hline
\end{tabular}

Table 2. Sensors supported by RTTOV-gb as for October 2018 (v1.0) with the corresponding number of channels and their central frequency.

\begin{tabular}{|c|c|c|c|}
\hline Sensor & $\begin{array}{r}\text { RTTOV-gb } \\
\text { ID }\end{array}$ & $\begin{array}{r}\text { Number of } \\
\text { channels (no.) }\end{array}$ & $\begin{array}{l}\text { Channel frequencies } \\
(\mathrm{GHz})\end{array}$ \\
\hline HATPRO & 1 & 14 & $\begin{array}{l}22.24 ; 23.04 ; 23.84 ; 25.44 ; 26.24 ; 27.84 ; 31.40 ; 51.26 ; 52.28 \\
53.86 ; 54.94 ; 56.66 ; 57.30 ; 58.00\end{array}$ \\
\hline MP3000A & 2 & 22 & $\begin{array}{lllllll}22.234 ; & 22.500 ; & 23.034 ; & 23.834 ; & 25.000 ; & 26.234 ; & 28.000 \\
30.000 ; & 51.248 ; & 51.760 ; & 52.280 ; & 52.804 ; & 53.336 ; & 53.848 \\
54.400 ; & 54.940 ; & 55.500 ; & 56.020 ; & 56.660 ; & 57.288 ; & 57.964 \\
58.800 ; & & & & & \end{array}$ \\
\hline TEMPERA & 3 & 12 & $\begin{array}{l}51.25 ; 51.75 ; 52.25 ; 52.85 ; 53.35 ; 53.85 ; 54.40 ; 54.90 ; 55.40 ; \\
56.00 ; 56.50 ; 57.00\end{array}$ \\
\hline LWP_K2W & 4 & 6 & $23.84 ; 31.40 ; 72.50 ; 82.50 ; 90.0 ; 150.0$ \\
\hline
\end{tabular}

resents the standard deviation of typical spectroscopic uncertainties to be expected from $\boldsymbol{T}_{\mathrm{B}}$ computed with the R17 model. Figure 2 shows $\sigma\left(\boldsymbol{T}_{\mathrm{B}}\right)$ for zenith observations in six climatological atmospheric conditions. Note that the uncertainties used here are at the $1 \sigma$ level, i.e., applying a unitary coverage factor ( $k=1$, as defined by JCGM, 2008).

Note that the analysis of Cimini et al. (2018) was limited to the $20-60 \mathrm{GHz}$ range. Here, a new sensitivity analysis has been performed to cover the frequency range of sensors available for RTTOV-gb v1.0 (20 to $150 \mathrm{GHz}$ ). One additional parameter was found to contribute dominantly, namely the temperature-dependence exponent $n_{\mathrm{cs}}$ of the water vapor self-broadened continuum, contributing with its uncertainty by $0.2-0.6 \mathrm{~K}$ to the total uncertainty of downwelling $\boldsymbol{T}_{\mathrm{B}}$ between 70 and $150 \mathrm{GHz}$. By applying the same approach as described in Cimini et al. (2018) for other water vapor continuum parameters, the covariance and correlation between $n_{\mathrm{cs}}$ and the self-broadened continuum parameter $C_{\mathrm{s}}$ were estimated to be $\operatorname{Cov}\left(C_{\mathrm{s}}, n_{\mathrm{cs}}\right)=-3.6208 \times$ $10^{-10}\left(\mathrm{~km}^{-1} \mathrm{hPa}^{-2} \mathrm{GHz}^{-2}\right)$ and $\operatorname{Cor}\left(C_{\mathrm{s}}, n_{\mathrm{cs}}\right)=-0.183$, respectively. The covariance of $n_{\mathrm{cs}}$ with respect to the other 111 parameters is estimated to be negligible.

For more details on RTTOV and the differences between RTTOV-gb and RTTOV, see Hocking et al. (2015), Saunders et al. (2018), and De Angelis et al. (2016).

\section{Validation with reference model and real observations}

The accuracy of RTTOV-gb v1.0 $\boldsymbol{T}_{\mathrm{B}}$ simulations has been tested against both the reference LBL model and real groundbased observations.

\subsection{Validation against reference model}

As described by De Angelis et al. (2016), the approach for testing RTTOV-gb against the reference LBL model used for training (i.e., R98 or R17) consists of computing $\boldsymbol{T}_{\mathrm{B}}$ sim- 
Table 3. Statistics for the comparison between RTTOV-gb and the line-by-line model R98 (Rosenkranz, 1998) used for training against an independent profile set. The TEMPERA instrument channel number (Chan no.), the channel central frequency, bias, and rms at four elevation angles are reported.

\begin{tabular}{|c|c|c|c|c|c|c|c|c|c|}
\hline \multirow[t]{2}{*}{ Chan no. } & \multirow[t]{2}{*}{$\begin{array}{r}\text { Central frequency } \\
(\mathrm{GHz})\end{array}$} & \multicolumn{4}{|c|}{$\begin{array}{l}\text { Bias } \\
(\mathrm{K})\end{array}$} & \multicolumn{4}{|c|}{$\begin{array}{r}\mathrm{rms} \\
(\mathrm{K})\end{array}$} \\
\hline & & $90^{\circ}$ & $30^{\circ}$ & $19^{\circ}$ & $10^{\circ}$ & $90^{\circ}$ & $30^{\circ}$ & $19^{\circ}$ & $10^{\circ}$ \\
\hline 1 & 51.250 & -0.003 & -0.019 & -0.018 & -0.043 & 0.153 & 0.158 & 0.125 & 0.077 \\
\hline 2 & 51.750 & -0.003 & -0.016 & -0.012 & -0.031 & 0.160 & 0.148 & 0.104 & 0.049 \\
\hline 3 & 52.250 & -0.004 & -0.010 & -0.006 & -0.020 & 0.167 & 0.131 & 0.077 & 0.029 \\
\hline 4 & 52.850 & -0.003 & 0.001 & -0.002 & -0.010 & 0.165 & 0.093 & 0.041 & 0.019 \\
\hline 5 & 53.350 & -0.001 & 0.006 & -0.003 & -0.004 & 0.141 & 0.054 & 0.021 & 0.015 \\
\hline 6 & 53.850 & -0.001 & 0.002 & -0.001 & -0.002 & 0.095 & 0.026 & 0.015 & 0.012 \\
\hline 7 & 54.400 & 0.001 & -0.002 & -0.001 & -0.001 & 0.047 & 0.015 & 0.011 & 0.007 \\
\hline 8 & 54.900 & 0.002 & 0.000 & -0.000 & -0.000 & 0.024 & 0.011 & 0.008 & 0.004 \\
\hline 9 & 55.400 & 0.002 & 0.001 & 0.000 & -0.000 & 0.017 & 0.008 & 0.005 & 0.002 \\
\hline 10 & 56.000 & 0.003 & 0.000 & 0.000 & 0.000 & 0.013 & 0.005 & 0.003 & 0.001 \\
\hline 11 & 56.500 & 0.002 & 0.001 & 0.000 & 0.000 & 0.011 & 0.004 & 0.002 & 0.001 \\
\hline 12 & 57.000 & 0.002 & 0.000 & 0.000 & 0.000 & 0.009 & 0.003 & 0.001 & 0.000 \\
\hline
\end{tabular}

Table 4. Same as Table 3 but for the LWP_K2W instrument.

\begin{tabular}{|c|c|c|c|c|c|c|c|c|c|}
\hline \multirow[t]{2}{*}{ Chan no. } & \multirow[t]{2}{*}{$\begin{array}{r}\text { Central frequency } \\
(\mathrm{GHz})\end{array}$} & \multicolumn{4}{|c|}{$\begin{array}{c}\text { Bias } \\
(\mathrm{K})\end{array}$} & \multicolumn{4}{|c|}{$\begin{array}{l}\mathrm{rms} \\
(\mathrm{K})\end{array}$} \\
\hline & & $90^{\circ}$ & $30^{\circ}$ & $19^{\circ}$ & $10^{\circ}$ & $90^{\circ}$ & $30^{\circ}$ & $19^{\circ}$ & $10^{\circ}$ \\
\hline 1 & 23.840 & 0.008 & 0.004 & -0.009 & -0.086 & 0.027 & 0.032 & 0.040 & 0.141 \\
\hline 2 & 31.400 & 0.008 & -0.004 & -0.011 & -0.107 & 0.035 & 0.044 & 0.059 & 0.302 \\
\hline 3 & 72.500 & 0.007 & -0.027 & -0.038 & -0.094 & 0.146 & 0.155 & 0.170 & 0.185 \\
\hline 4 & 82.500 & 0.027 & -0.024 & -0.043 & -0.078 & 0.138 & 0.138 & 0.174 & 0.238 \\
\hline 5 & 90.000 & 0.030 & -0.025 & -0.045 & -0.067 & 0.148 & 0.140 & 0.180 & 0.251 \\
\hline 6 & 150.000 & -0.006 & -0.061 & -0.044 & 0.077 & 0.172 & 0.133 & 0.157 & 0.301 \\
\hline
\end{tabular}

ulations with both models from a set of independent profiles (i.e., not used for training) and to evaluate the statistics of their difference, namely the mean (bias) and root-meansquare (rms) difference. For the original two sensors (HATPRO and MP3000A), De Angelis et al. (2016) in their Tables 2 and 3 reported the statistics (bias and rms) for the comparison between RTTOV-gb and the LBL model used for training (R98 in their case) against an independent profile set at four elevation angles $\left(90,30,19\right.$, and $\left.10^{\circ}\right)$. Similarly, here we report the statistics for the two new sensors (i.e., TEMPERA and LWP_K2W) and the same R98 LBL model, respectively, in Tables 3 and 4 . These two tables show that the discrepancies between RTTOV-gb v1.0 and LBL optical depths lead to negligible $\boldsymbol{T}_{\mathrm{B}}$ differences. The rms differences at zenith are lower than $0.18 \mathrm{~K}$ for all channels. When decreasing the elevation angle, the rms differences generally decrease for 50-57 GHz channels (Table 3), while they increase for 23-31 and 70-150 GHz channels (Table 4), in accordance with the different levels of atmospheric opacity. The highest rms differences $(0.3 \mathrm{~K})$ are found for window channels 31 and $150 \mathrm{GHz}$ at $10^{\circ}$ elevation. Similarly to De
Angelis et al. (2016), the main conclusion is that the uncertainty introduced by the fast model approximation (RTTOV$\mathrm{gb}$ ) is within the typical instrument uncertainty and thus does not dominate the uncertainty budget of observations vs. simulations. Let us underline that Tables 2 and 3 of De Angelis et al. (2016) and Tables 3 and 4 of this paper report statistics when using the R98 LBL model for training. The analogous rms values obtained using the LBL model R17 at zenith are reported in Table 5 as "fast parameterization uncertainty". As expected, rms values do not differ significantly from those obtained against R98. In fact, this test only tells us about the accuracy of the parameterized regression in reproducing the LBL model radiances, which is largely independent of the choice of the LBL model. Table 5 also reports the $\boldsymbol{T}_{\mathrm{B}}$ uncertainty contribution due to the uncertainty of spectroscopic parameters (from Fig. 2). The estimated total uncertainty is computed as the sum in quadrature (i.e., the square root of the sum of squares) of two contributions: the uncertainty due to fast parameterization and absorption model spectroscopic parameters. The latter dominates the uncertainty budget. The 


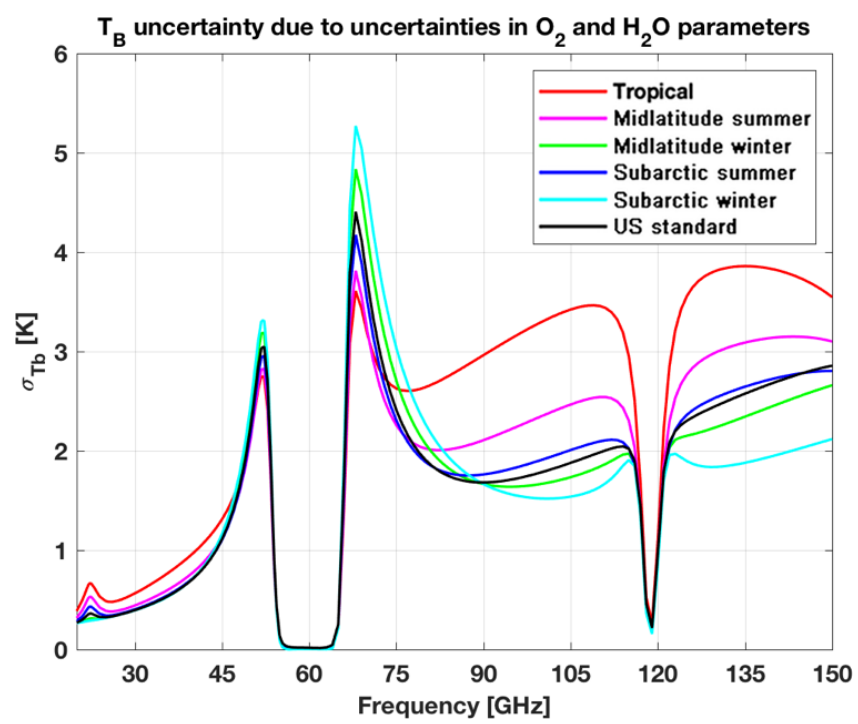

Figure 2. Zenith downwelling $\boldsymbol{T}_{\mathrm{B}}$ uncertainty $\left(\sigma\left(T_{\mathrm{B}}\right)\right)$ due to the uncertainty in $\mathrm{O}_{2}$ and $\mathrm{H}_{2} \mathrm{O}$ absorption model parameters. Six climatological atmospheric conditions (color-coded) have been used to compute $\operatorname{Cov}(p)$ (see Sect. 2.2). $\boldsymbol{\sigma}\left(\boldsymbol{T}_{\mathrm{B}}\right)$ is computed as the square root of the diagonal terms of $\operatorname{Cov}\left(\boldsymbol{T}_{\mathrm{B}}\right)$. This figure is similar to Fig. 6 in Cimini et al. (2018), although $\boldsymbol{\sigma}\left(\boldsymbol{T}_{\mathrm{B}}\right)$ was recomputed to cover a wider frequency range.

total uncertainty so estimated is reported in Table 5 for each sensor and channel available in RTTOV-gb.

\subsection{Validation against real observations}

RTTOV-gb $\boldsymbol{T}_{\mathrm{B}}$ simulations have been previously compared with real ground-based observations from six HATPRO and one MP3000-A (De Angelis et al., 2016, 2017). The frequency range covered by HATPRO and MP3000-A channels overlaps the frequency range of TEMPERA, so we assume RTTOV-gb has been tested for this sensor as well. Conversely, the frequency range of LWP_K2W extends to higher frequencies (up to $150 \mathrm{GHz}$ ) to include all the channels offered by the RPG LWP ground-based radiometer family (LWP, LWP-U90, LWP-U72-82, LWP-U150, LWP-90150). Thus, in the following we present a comparison with observations from an LWP-U72-82 radiometer located at the Polytechnic University campus in Milan (Italy; $45.450^{\circ} \mathrm{N}$, 9.183 ${ }^{\circ}$ E), and from an LWP-90-150 radiometer located at the Atmospheric Radiation Measurement (ARM) program Southern Great Plains (SGP) central facility in Lamont (OK, USA; $36.605^{\circ} \mathrm{N}, 97.485^{\circ} \mathrm{W}$ ). The two datasets represent midlatitude summer and midlatitude winter conditions. Operational radiosondes are launched from these two sites, measuring profiles of pressure, temperature, and water vapor, which are then processed by RTTOV-gb to compute downwelling $\boldsymbol{T}_{\mathrm{B}}$ simulating ground-based observations. Since these radiosondes do not measure liquid water content profiles, we assume no clouds are present and thus meaningful

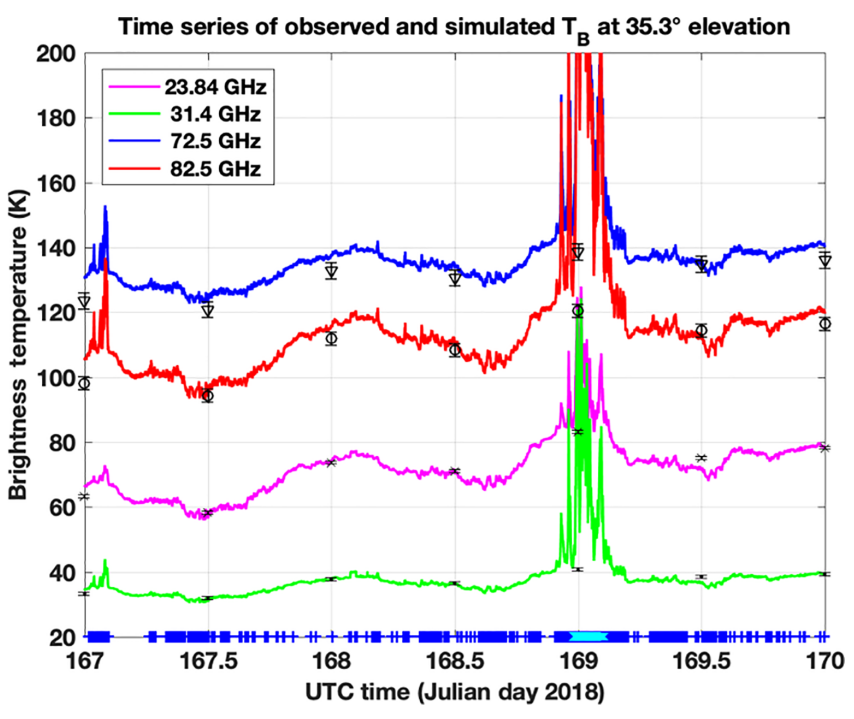

Figure 3. Time series of observed (lines) and simulated (markers) $\boldsymbol{T}_{\mathrm{B}}$ at $35.3^{\circ}$ elevation for four channels of LWP-U72-82. The radiometer is located at the Polytechnic University campus in Milan (Italy), while radiosondes used for the simulations are launched from the Milan Linate airport ( $\sim 20 \mathrm{~km}$ from the Polytechnic University campus). Channel frequencies are color-coded as reported in the legend. Simulations are reported with dots $(23.84 \mathrm{GHz})$, crosses $(31.4 \mathrm{GHz})$, triangles $(72.5 \mathrm{GHz})$, and circles $(82.5 \mathrm{GHz})$, including an indicative estimate of the total uncertainty. The cloud and rain flags are indicated at the bottom by blue and cyan crosses, respectively. The time series spans the period of 00:00 of 16 June (Julian day 167) to 00:00 of 19 June (Julian day 170) 2018.

comparison with real observations can be performed in clear sky only. Radiosondes usually reach up to $10 \mathrm{hPa}(\sim 30 \mathrm{~km}$ altitude), leaving the five uppermost RTTOV-gb levels to be covered with climatological profiles. This has negligible impact on ground-based radiance calculations.

The LWP-U72-82 instrument has four channels (23.84, $31.4,72.5$, and $82.5 \mathrm{GHz}$ ), and it is mainly used for radio propagation studies. The available dataset extends for 1 month (from 16 June to 15 July 2018), corresponding to relatively moist midlatitude summer conditions. The dataset includes radiometric observations and pressure, temperature, and humidity profiles measured by radiosonde ascents launched twice daily from the Milan Linate airport $(\sim 20 \mathrm{~km}$ from the Polytechnic University campus). Radiometric observations are collected at a fixed elevation angle $\left(35.3^{\circ}\right)$, matching the direction of the Alphasat telecommunication link. Absolute MWR calibrations were performed 9 months earlier and 4 months later than the period under study, showing no substantial change in the calibration coefficients. Thus, we assume the calibration was stable during the period under study. An example of data is shown in Fig. 3 for 3 consecutive days. Here, $\boldsymbol{T}_{\mathrm{B}}$ observed at the four channels is plotted together with RTTOV-gb simulations and their estimated uncertainty. It appears that simulations usually fit 
Table 5. RTTOV-gb $\boldsymbol{T}_{\mathrm{B}}$ uncertainty due to forward model and fast parameterization and their total squared sum for two extreme climatology conditions. Channels for the four sensors considered in the current version of RTTOV-gb are given in (a) (HATPRO), (b) (MP3000A), (c) (TEMPERA), and (d) (LWP_K2W). Values are given for zenith observations.

\begin{tabular}{|c|c|c|c|c|c|c|}
\hline \multicolumn{7}{|c|}{ (a) HATPRO } \\
\hline \multirow[t]{2}{*}{ Chan no. } & \multirow[t]{2}{*}{$\begin{array}{r}\text { Central frequency } \\
(\mathrm{GHz})\end{array}$} & \multirow[t]{2}{*}{$\begin{array}{r}\text { Fast parameterization } \\
\text { uncertainty }(\mathrm{K})\end{array}$} & \multicolumn{2}{|c|}{$\begin{array}{l}\text { Absorption model } \\
\text { uncertainty }(\mathrm{K})\end{array}$} & \multicolumn{2}{|c|}{$\begin{array}{l}\text { Total uncertainty } \\
\qquad(\mathrm{K})\end{array}$} \\
\hline & & & Tropical & $\begin{array}{r}\text { Subarctic } \\
\text { winter }\end{array}$ & Tropical & $\begin{array}{r}\text { Subarctic } \\
\text { winter }\end{array}$ \\
\hline 1 & 22.240 & 0.037 & 0.665 & 0.290 & 0.666 & 0.292 \\
\hline 2 & 23.040 & 0.030 & 0.621 & 0.296 & 0.621 & 0.297 \\
\hline 3 & 23.840 & 0.026 & 0.542 & 0.303 & 0.543 & 0.304 \\
\hline 4 & 25.440 & 0.028 & 0.480 & 0.322 & 0.481 & 0.323 \\
\hline 5 & 26.240 & 0.027 & 0.480 & 0.332 & 0.481 & 0.333 \\
\hline 6 & 27.840 & 0.026 & 0.506 & 0.356 & 0.506 & 0.357 \\
\hline 7 & 31.400 & 0.030 & 0.609 & 0.420 & 0.610 & 0.421 \\
\hline 8 & 51.260 & 0.148 & 2.623 & 3.119 & 2.628 & 3.123 \\
\hline 9 & 52.280 & 0.167 & 2.727 & 3.301 & 2.732 & 3.305 \\
\hline 10 & 53.860 & 0.094 & 1.003 & 1.132 & 1.007 & 1.136 \\
\hline 11 & 54.940 & 0.024 & 0.126 & 0.089 & 0.128 & 0.093 \\
\hline 12 & 56.660 & 0.011 & 0.023 & 0.001 & 0.026 & 0.011 \\
\hline 13 & 57.300 & 0.009 & 0.019 & 0.003 & 0.021 & 0.009 \\
\hline 14 & 58.000 & 0.008 & 0.018 & 0.003 & 0.020 & 0.009 \\
\hline
\end{tabular}

(b) MP3000

\begin{tabular}{|c|c|c|c|c|c|c|}
\hline \multirow[t]{2}{*}{ Chan no. } & \multirow[t]{2}{*}{$\begin{array}{r}\text { Central frequency } \\
(\mathrm{GHz})\end{array}$} & \multirow[t]{2}{*}{$\begin{array}{r}\text { Fast parameterization } \\
\text { uncertainty }(\mathrm{K})\end{array}$} & \multicolumn{2}{|c|}{$\begin{array}{l}\text { Absorption model } \\
\text { uncertainty }(\mathrm{K})\end{array}$} & \multicolumn{2}{|c|}{$\begin{array}{l}\text { Total uncertainty } \\
\qquad(\mathrm{K})\end{array}$} \\
\hline & & & Tropical & $\begin{array}{r}\text { Subarctic } \\
\text { winter }\end{array}$ & Tropical & $\begin{array}{r}\text { Subarctic } \\
\text { winter }\end{array}$ \\
\hline 1 & 22.234 & 0.037 & 0.665 & 0.290 & 0.666 & 0.292 \\
\hline 2 & 22.500 & 0.036 & 0.663 & 0.292 & 0.664 & 0.294 \\
\hline 3 & 23.034 & 0.030 & 0.621 & 0.296 & 0.622 & 0.297 \\
\hline 4 & 23.834 & 0.026 & 0.543 & 0.303 & 0.543 & 0.304 \\
\hline 5 & 25.000 & 0.028 & 0.487 & 0.316 & 0.487 & 0.317 \\
\hline 6 & 26.234 & 0.027 & 0.480 & 0.332 & 0.481 & 0.333 \\
\hline 7 & 28.000 & 0.026 & 0.509 & 0.358 & 0.510 & 0.359 \\
\hline 8 & 30.000 & 0.028 & 0.564 & 0.393 & 0.565 & 0.394 \\
\hline 9 & 51.248 & 0.148 & 2.619 & 3.114 & 2.624 & 3.117 \\
\hline 10 & 51.760 & 0.157 & 2.744 & 3.299 & 2.749 & 3.302 \\
\hline 11 & 52.280 & 0.166 & 2.727 & 3.301 & 2.732 & 3.305 \\
\hline 12 & 52.804 & 0.165 & 2.434 & 2.943 & 2.440 & 2.948 \\
\hline 13 & 53.336 & 0.141 & 1.793 & 2.129 & 1.798 & 2.134 \\
\hline 14 & 53.848 & 0.094 & 1.020 & 1.153 & 1.024 & 1.156 \\
\hline 15 & 54.400 & 0.046 & 0.390 & 0.388 & 0.393 & 0.391 \\
\hline 16 & 54.940 & 0.024 & 0.126 & 0.089 & 0.128 & 0.093 \\
\hline 17 & 55.500 & 0.016 & 0.052 & 0.018 & 0.054 & 0.024 \\
\hline 18 & 56.020 & 0.013 & 0.033 & 0.004 & 0.035 & 0.014 \\
\hline 19 & 56.660 & 0.011 & 0.023 & 0.001 & 0.026 & 0.011 \\
\hline 20 & 57.288 & 0.009 & 0.019 & 0.003 & 0.021 & 0.009 \\
\hline 21 & 57.964 & 0.008 & 0.018 & 0.003 & 0.020 & 0.009 \\
\hline 22 & 58.800 & 0.007 & 0.018 & 0.004 & 0.019 & 0.008 \\
\hline
\end{tabular}


Table 5. Continued.

\begin{tabular}{|c|c|c|c|c|c|c|}
\hline \multicolumn{7}{|c|}{ (c) TEMPERA } \\
\hline \multirow[t]{2}{*}{ Chan no. } & \multirow[t]{2}{*}{$\begin{array}{r}\text { Central frequency } \\
(\mathrm{GHz})\end{array}$} & \multirow[t]{2}{*}{$\begin{array}{r}\text { Fast parameterization } \\
\text { uncertainty }(\mathrm{K})\end{array}$} & \multicolumn{2}{|c|}{$\begin{array}{c}\text { Absorption model } \\
\text { uncertainty }(\mathrm{K})\end{array}$} & \multicolumn{2}{|c|}{$\begin{array}{l}\text { Total uncertainty } \\
\qquad(\mathrm{K})\end{array}$} \\
\hline & & & Tropical & $\begin{array}{r}\text { Subarctic } \\
\text { winter }\end{array}$ & Tropical & $\begin{array}{r}\text { Subarctic } \\
\text { winter }\end{array}$ \\
\hline 1 & 51.250 & 0.148 & 2.620 & 3.115 & 2.624 & 3.118 \\
\hline 2 & 51.750 & 0.157 & 2.743 & 3.296 & 2.747 & 3.300 \\
\hline 3 & 52.250 & 0.166 & 2.733 & 3.307 & 2.738 & 3.311 \\
\hline 4 & 52.850 & 0.164 & 2.393 & 2.892 & 2.398 & 2.896 \\
\hline 5 & 53.350 & 0.141 & 1.773 & 2.104 & 1.778 & 2.109 \\
\hline 6 & 53.850 & 0.094 & 1.017 & 1.149 & 1.021 & 1.153 \\
\hline 7 & 54.400 & 0.046 & 0.390 & 0.388 & 0.393 & 0.391 \\
\hline 8 & 54.900 & 0.024 & 0.136 & 0.100 & 0.138 & 0.103 \\
\hline 9 & 55.400 & 0.017 & 0.059 & 0.023 & 0.061 & 0.029 \\
\hline 10 & 56.000 & 0.013 & 0.033 & 0.004 & 0.036 & 0.014 \\
\hline 11 & 56.500 & 0.011 & 0.025 & 0.000 & 0.027 & 0.011 \\
\hline 12 & 57.000 & 0.010 & 0.021 & 0.002 & 0.023 & 0.010 \\
\hline \multicolumn{7}{|c|}{ (d) LWP_K2W } \\
\hline \multirow[t]{2}{*}{ Chan no. } & \multirow[t]{2}{*}{$\begin{array}{r}\text { Central frequency } \\
(\mathrm{GHz})\end{array}$} & \multirow[t]{2}{*}{$\begin{array}{r}\text { Fast parameterization } \\
\text { uncertainty }(\mathrm{K})\end{array}$} & \multicolumn{2}{|c|}{$\begin{array}{c}\text { Absorption model } \\
\text { uncertainty }(\mathrm{K})\end{array}$} & \multicolumn{2}{|c|}{$\begin{array}{l}\text { Total uncertainty } \\
(\mathrm{K})\end{array}$} \\
\hline & & & Tropical & $\begin{array}{r}\text { Subarctic } \\
\text { winter }\end{array}$ & Tropical & $\begin{array}{r}\text { Subarctic } \\
\text { winter }\end{array}$ \\
\hline 1 & 23.840 & 0.026 & 0.542 & 0.303 & 0.543 & 0.304 \\
\hline 2 & 31.400 & 0.030 & 0.609 & 0.420 & 0.610 & 0.421 \\
\hline 3 & 72.500 & 0.139 & 2.775 & 3.690 & 2.778 & 3.692 \\
\hline 4 & 82.500 & 0.119 & 2.706 & 2.042 & 2.708 & 2.045 \\
\hline 5 & 90.000 & 0.126 & 2.963 & 1.665 & 2.966 & 1.669 \\
\hline 6 & 150.000 & 0.161 & 3.547 & 2.118 & 3.550 & 2.124 \\
\hline
\end{tabular}

the observations within uncertainty, except for periods with clouds (at $\sim 167.0$, i.e., 00:00 of 16 June) and rain $(\sim 169.0$, i.e., 00:00 of 18 June). This is expected as RTTOV-gb simulations are computed from radiosonde measurements, which do not provide hydrometeor content and thus do not take into account the radiative contribution of clouds and rain. Thus, for a fair clear-sky comparison, data affected by either rain or clouds must be screened out. As illustrated in Fig. 3, the LWP-U72-82 is equipped with a rain sensor, indicating either rain or no rain on the antenna radome. Observations during rain, as flagged by the rain sensor, have been discarded. In addition, cloudy conditions have been identified by setting a threshold on the standard deviation of $\boldsymbol{T}_{\mathrm{B}}(31.4 \mathrm{GHz})$ over a time period (Turner et al., 2007). This approach has been used previously with a $0.5 \mathrm{~K}$ threshold over a $1 \mathrm{~h}$ period (De Angelis et al., 2017). Here, we choose a shorter period (10 min); assuming lower clear-sky atmospheric variability with decreasing time interval, and looking at the distribution of the $\boldsymbol{T}_{\mathrm{B}}(31.4 \mathrm{GHz})$ standard deviation, we set the threshold to $0.2 \mathrm{~K}$. Thus, data identified as cloudy, by the standard deviation of $\boldsymbol{T}_{\mathrm{B}}(31.4 \mathrm{GHz})$ over a $10 \mathrm{~min}$ pe- riod being larger than $0.2 \mathrm{~K}$, have been discarded. The cloud and rain screening reduced the dataset by $\sim 33 \%$, leaving 40 matchups between clear-sky radiosonde and radiometric observations (averaged within \pm 5 min from the radiosonde launch). Scatterplots of simulated vs. observed $\boldsymbol{T}_{\mathrm{B}}$ at $35.3^{\circ}$ elevation for the four channels of LWP-U72-82 are shown in Fig. 4. Note that the correlation coefficient is 0.98 for all four channels. The slope is within $5 \%$ for all channels but $72.5 \mathrm{GHz}(\sim 8 \%)$, for which the difference between observations and simulations tends to increase as $\boldsymbol{T}_{\mathrm{B}}$ decrease. This may be due to an issue with the instrument gain calibration as well as to increasing uncertainty for this channel at lower temperature and moisture conditions (see Fig. 2). Statistics at 23.84 and $31.4 \mathrm{GHz}$ are of the same magnitude as those reported by De Angelis et al. (2017) at $30^{\circ}$ elevation (their Fig. 5c).

The LWP-90-150 instrument has two channels (90.0 and $150.0 \mathrm{GHz}$ ), and it is mainly used for the retrieval of total column cloud liquid water content. The instrument considered here has been running at the ARM SGP central facility between November 2006 and November 2013, performing 

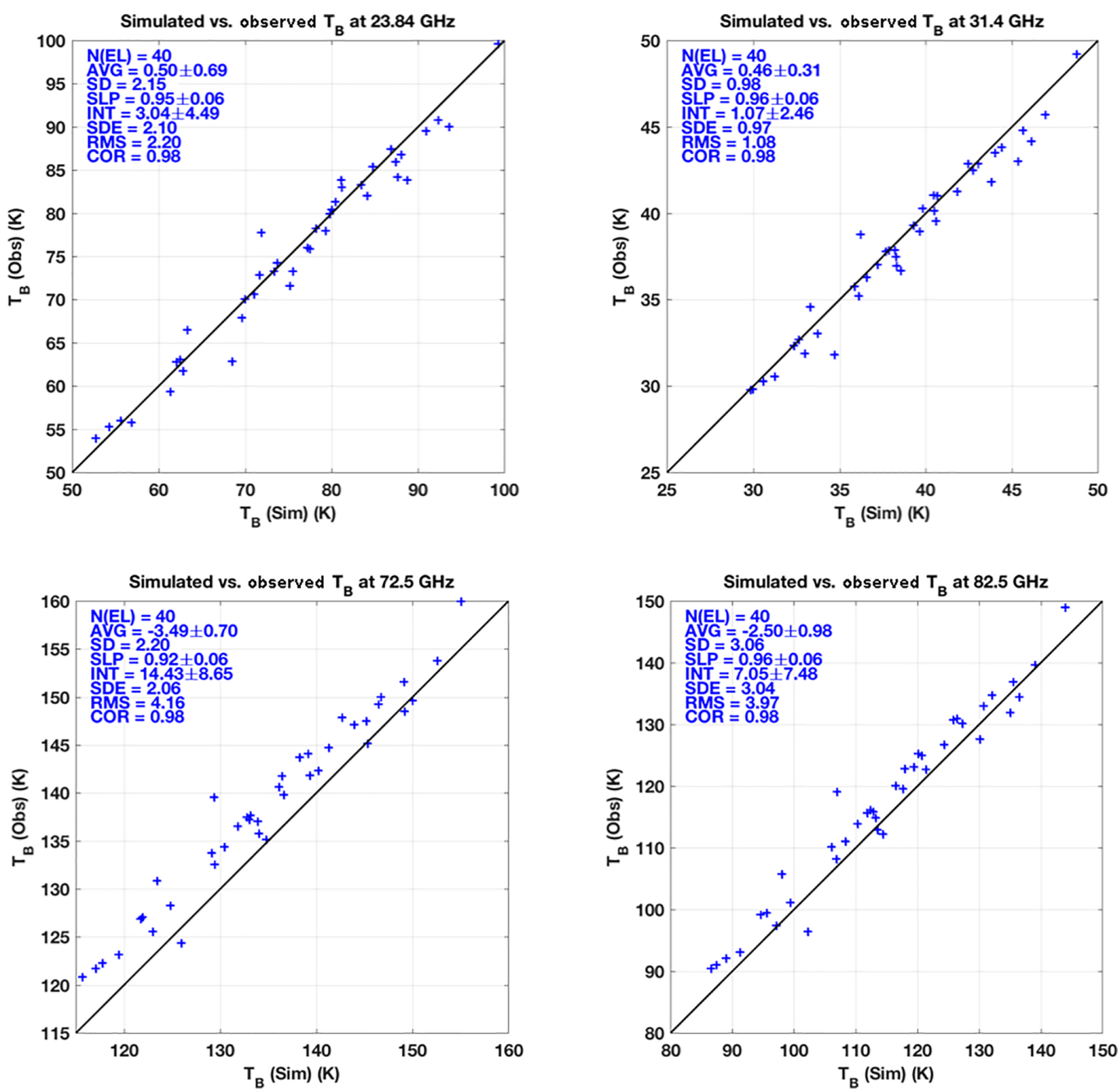

Figure 4. Scatter of simulated vs. observed $\boldsymbol{T}_{\mathrm{B}}$ at $35.3^{\circ}$ elevation for four channels of LWP-U72-82. Locations of radiometer and radiosondes are as in Fig. 3. The absorption model of Rosenkranz (2017) has been used. Each panel reports the number of elements $(N(E L))$, the average difference (AVG), the standard deviation (SD), the slope (SLP) and intercept (INT) of a linear fit, the standard error (SDE), the root-mean square (rms), and correlation coefficient (COR); $95 \%$ confidence intervals are given for AVG, SLP, and INT. Units for AVG, SD, SDE, and rms are in kelvin.

calibrations regularly using the tip curve method (Cadeddu et al., 2013). Here we exploit a 2-month dataset of radiometric and radiosonde observations (ARM, 2018a, b) collected in January-February 2012. This dataset corresponds to relatively dry midlatitude winter conditions. An example of data is shown in Fig. 5 for 3 consecutive days, corresponding to a dry clear-sky period with intermittent thick clouds and rain. Observations flagged by the rain sensor have been discarded. In addition, cloudy conditions have been identified with the same approach as described above, i.e., setting a threshold on the $10 \mathrm{~min}$ standard deviation of $\boldsymbol{T}_{\mathrm{B}}$ at a window channel, here replacing the $31.4 \mathrm{GHz}$ with the $90.0 \mathrm{GHz}$ channel. However, since $\boldsymbol{T}_{\mathrm{B}}(90 \mathrm{GHz})$ has $\sim 6$ times larger sensitivity to water vapor (Cimini et al., 2007), the clear-sky thresh- old is increased by the same factor, i.e., $1.2 \mathrm{~K}$. Thus, data with 10 min standard deviation of $\boldsymbol{T}_{\mathrm{B}}(90 \mathrm{GHz})$ larger than $1.2 \mathrm{~K}$ have been discarded. The cloud and rain screening reduced the dataset by $\sim 26 \%$, leaving 173 matchups between clear-sky radiosonde and radiometric observations (averaged within \pm 5 min from the radiosonde launch). Scatterplots of simulated vs. observed $\boldsymbol{T}_{\mathrm{B}}$ at $90^{\circ}$ elevation for the two channels of LWP-90-150 are shown in Figure 6. The correlation coefficient is 0.95 and 0.99 for 90 and $150 \mathrm{GHz}$, respectively, while the slope is within $4 \%$ for both channels.

Overall, the average differences at all the six LWP_K2W channels are close to the accuracy estimated in Table 5d. A direct comparison is given in Fig. 7. Here, the estimated uncertainty for the six LWP_K2W channels is compared with 


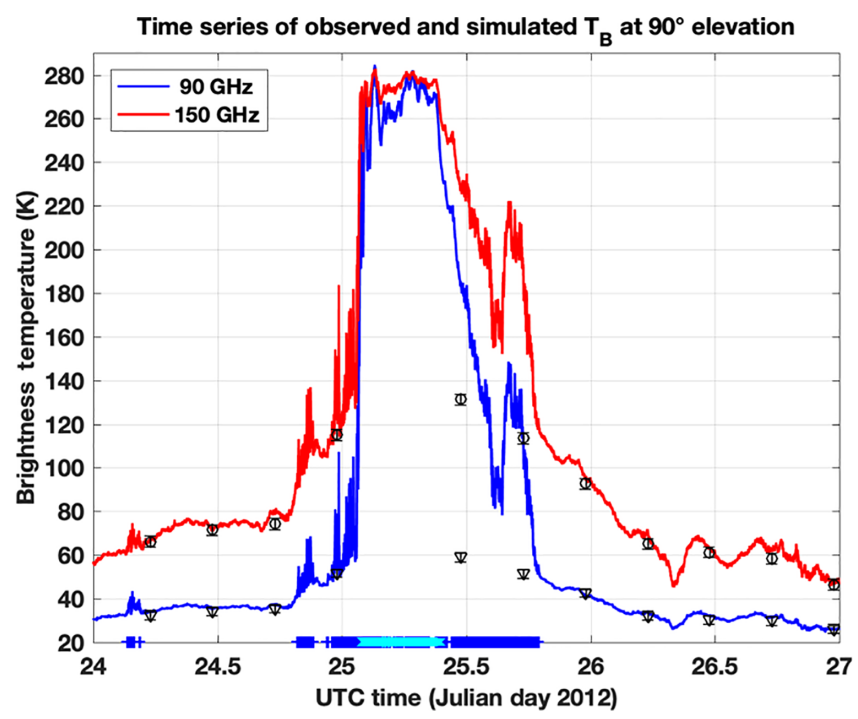

Figure 5. Time series of observed (lines) and simulated (markers) $\boldsymbol{T}_{\text {B }}$ at $90^{\circ}$ elevation for two channels of LWP-90-150. The radiometer and radiosondes are operated from the Atmospheric Radiation Measurement (ARM) program Southern Great Plains (SGP) central facility (Lamont, OK, USA). Channel frequencies are color-coded as reported in the legend. Simulations are reported with triangles $(90 \mathrm{GHz})$ and circles $(150 \mathrm{GHz})$, including an indicative estimate of the total uncertainty. The cloud and rain flags are indicated at the bottom by blue and cyan crosses, respectively. The time series spans 24 January 00:00 to 27 January 00:00 UTC 2012 (Julian day 24-27).

the experimental mean difference between simulations and observations. Note that radiometric observations at the four lower-frequency channels were collected in June-July in Milan $\left(45^{\circ} \mathrm{N}\right)$, while in January-February in Lamont $\left(36^{\circ} \mathrm{N}\right)$ they were collected at the two higher-frequency channels. Thus, the simulation uncertainty is estimated using midlatitude summer conditions for the four lower-frequency channels, while midlatitude winter conditions were used for the two higher-frequency channels. The experimental bias is generally larger than the simulation-estimated uncertainty, as one would expect since the observations are also affected by uncertainty. Except for the $72.5 \mathrm{GHz}$ channel, the estimated uncertainty and experimental bias are within $0.5 \mathrm{~K}$, which corresponds to the absolute $\boldsymbol{T}_{\mathrm{B}}$ accuracy claimed by the manufacturer for the LWP radiometer series. At $72.5 \mathrm{GHz}$, as anticipated, observation-simulation differences tend to increase as $\boldsymbol{T}_{\mathrm{B}}$ decreases, possibly due to either conditiondependent uncertainty or an issue with the instrument gain calibration. This will be the subject of a future investigation.

\section{Summary and future developments}

RTTOV-gb v1.0 is now freely available, after website registration (see section code and data availability). The updates with respect to the original development (described in De Angelis et al., 2016) are presented here, including two additional sensors, an additional parameterization for the training atmospheric absorption model, and an estimate of the $\boldsymbol{T}_{\mathrm{B}}$ uncertainty.

RTTOV-gb v1.0 has been trained and validated against two versions of a reference line-by-line absorption model, i.e., R98 (Rosenkranz, 1998) and R17 (Rosenkranz, 2017). In the frequency range commonly covered by RTTOV-gb v1.0 sensors, $\boldsymbol{T}_{\mathrm{B}}$ rms differences are smaller than typical sensor uncertainties at all considered channels and for both the reference absorption models. $\boldsymbol{T}_{\mathrm{B}}$ computed with RTTOVgb v1.0 from radiosonde profiles have been compared with simultaneous ground-based radiometric observations at six channels $(23.84,31.4,72.5,82.5,90.0$, and $150.0 \mathrm{GHz})$ and two observing elevation angles $\left(35.3\right.$ and $\left.90^{\circ}\right)$. Differences between simulated and measured $\boldsymbol{T}_{\mathrm{B}}$ are within uncertainty as expected from instrumental and simulation contributions. Future developments include additional sensors (e.g., at $183 \mathrm{GHz}$ ) and characterization of liquid water absorption uncertainties.

We expect this paper will provide a reference for the exploitation of RTTOV-gb for MWR data assimilation into NWP models, as has already started at some meteorological services in Europe as well as in other continents.

Code and data availability. RTTOV-gb v1.0 is available to licensed users free of charge. RTTOV-gb may be obtained by registering (https://www.nwpsaf.eu/site/register/, last access: 14 November 2018) with the NWP SAF website (https://www.nwpsaf.eu/, last access: 14 November 2018, NWP SAF, 2018) and then selecting RTTOV-gb in your software preferences. Instructions for compiling and running RTTOV-gb are provided in the RTTOV-gb User Guide within the software package. The software package also includes scripts to verify the installation and FORTRAN code examples for running the RTTOV-gb forward and K (Jacobian) modules. RTTOV-gb is designed for UNIX/Linux systems. The software is now successfully tested on the following architectures and Fortran 90 compilers: Intel systems with gfortran, ifort, NAG, and pgf90, and Apple Mac systems with gfortran.

The RTTOV-gb v1.0 code is based on RTTOV v11.2 and the programming interface is identical to that version of RTTOV, though some inputs and outputs are not used by RTTOV-gb. The original RTTOV v11.2 can be obtained from the NWP SAF website (http://nwpsaf.eu/site/software/rttov/ rttov-v11/, last access: 29 April 2019, Hocking and Rundle, 2019). Thus, the computational performances of RTTOV$\mathrm{gb}$ is similar to that of RTTOV v11.2, which have been reported (https://www.nwpsaf.eu/site/download/documentation/rtm/ docs_rttov11/Performance_Tests_RTTOV_v11.2.pdf, last access: 14 November 2018). For clear-sky microwave simulations, the main factor in simulation speed is the number of coefficient levels, which is 101 for RTTOV-gb. Typical clear-sky run times for RTTOV-gb are $\sim 0.25 \mathrm{~ms}$ per profile for the direct model and $\sim 1.0 \mathrm{~ms}$ per profile for the Jacobian model, though timings are dependent on the hardware, compiler, and compiler flags being used, as well as, for 

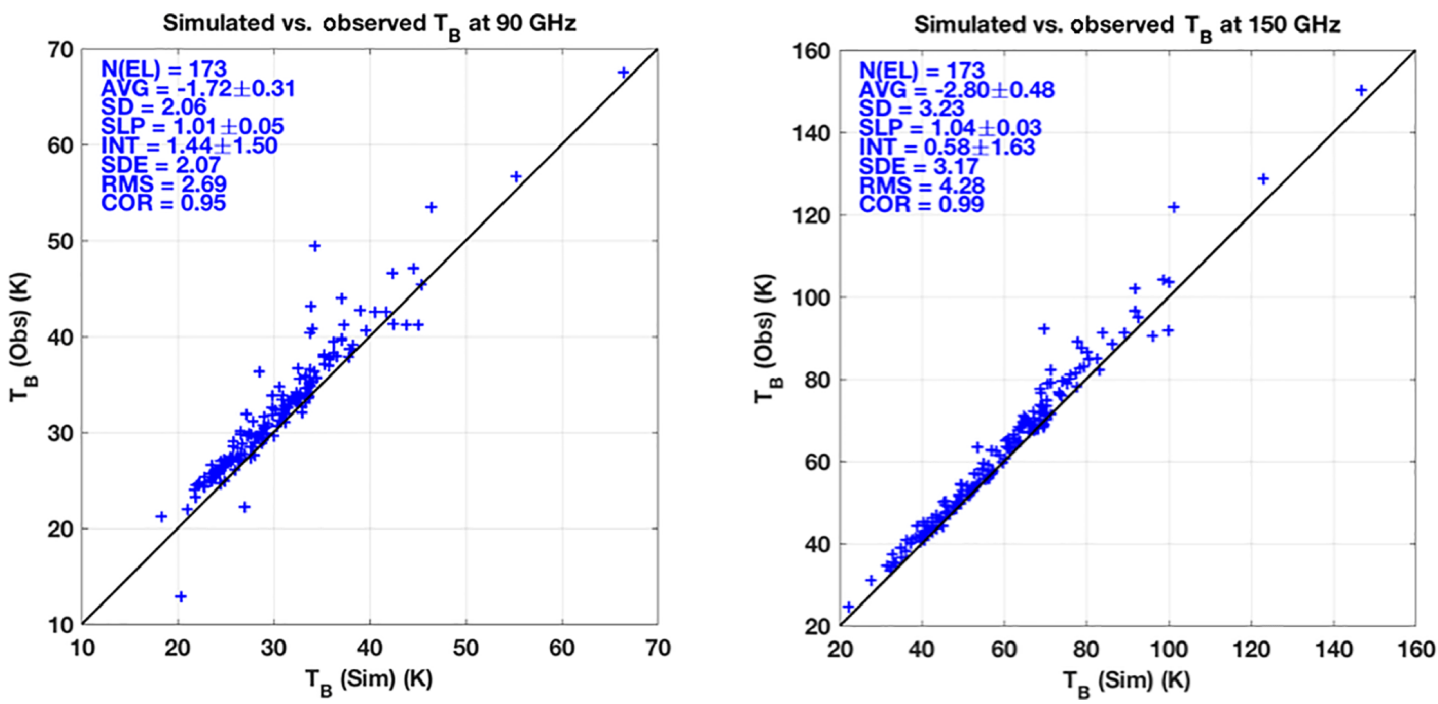

Figure 6. Same as Fig. 4 but showing simulated vs. observed $\boldsymbol{T}_{\mathrm{B}}$ at $90^{\circ}$ elevation for two channels of LWP-90-150. Location of radiometer and radiosondes are as in Fig. 5. The absorption model of Rosenkranz (2017) has been used.

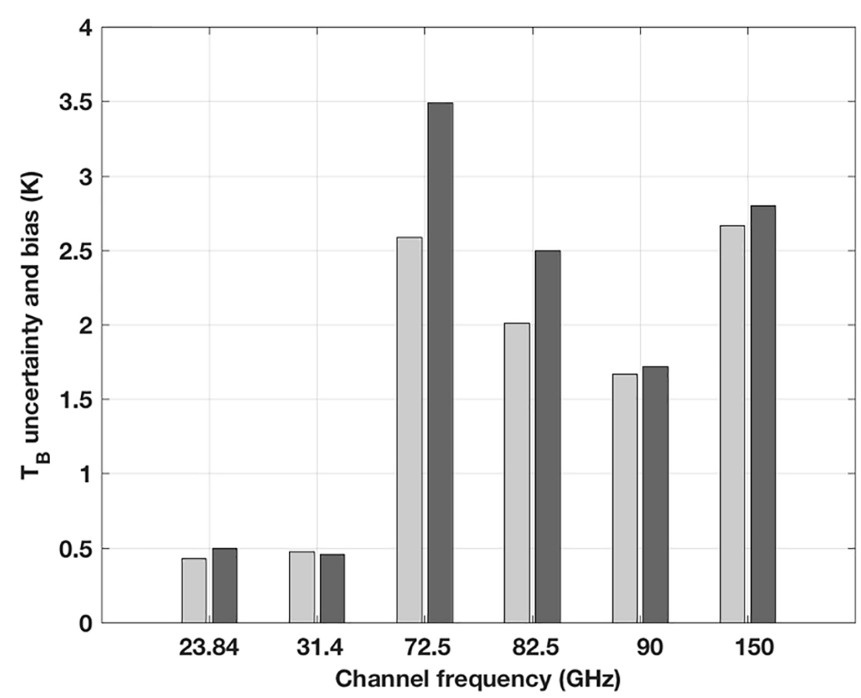

Figure 7. Estimated uncertainty (light grey) and experimental mean difference (dark grey) for six LWP_K2W channels. Radiometric observations were collected in June-July in Milan $\left(45^{\circ} \mathrm{N}\right)$ with the four lower-frequency channels, while they were collected in January-February in Lamont $\left(36^{\circ} \mathrm{N}\right)$ with the two higher-frequency channels. Thus, uncertainty is estimated using midlatitude summer conditions for the four lower-frequency channels, while midlatitude winter conditions are used for the two higher-frequency channels. example, the number of levels in the input profile, the number of channels simulated per profile, and the inclusion or not of cloud liquid water.

Note that RTTOV-gb is not supported by NWP SAF. All questions, bug reports, or requests for new coefficients should be sent to rttovgb@aquila.infn.it. Always refer to the RTTOV-gb web page for bug fixes, new coefficients, and code updates: http://cetemps.aquila. infn.it/rttovgb/rttovgb.html (Cimini, 2019).

The RTTOV-gb package contains optical depth coefficient files for sensors supported by RTTOV-gb at the time of release. Coefficients for sensors not currently considered can be requested from rttovgb@aquila.infn.it. Note that RTTOV-gb currently only supports microwave sensors. Other resources include

- default pressure levels: http://cetemps.aquila.infn.it/mwrnet/ main_files/DAT/RTTOVgb_101_levels_p.dat, last access: 14 November 2018

- regression coefficients: http://cetemps.aquila.infn.it/mwrnet/ rttovgb_coefficients.html, last access: 14 November 2018

- regression limits: http://cetemps.aquila.infn.it/mwrnet/main_ files/DAT/RTTOVgb_101_pressure_levels_and_regression_ limits.xlsx, last access: 29 April 2019

- NWP SAF profile sets used for the RTTOV-gb training and independent test: https://nwpsaf.eu/deliverables/rtm/profile_ datasets.html, last access: 29 April 2019 (Rundle, 2019).

For more information on reference profiles and regression limits see the related link on the official RTTOV website (https://www.nwpsaf.eu/site/software/rttov/download/coefficients/ coefficient-download/T1 1textbackslash\#Reference_profiles_and_ regression_limits).

Finally, the absorption model by Rosenkranz (2017) is available as a FORTRAN 77 code at https://doi.org/10.21982/M81013. Older versions, including the one used here (15 May 2017), are available at http://cetemps.aquila.infn.it/mwrnet/lblmrt_ns. html (last access: 14 November 2018). Microwave radiometer and radiosonde data in Lamont (OK, USA) are available 
through the Atmospheric Radiation Measurement (ARM) program (https://doi.org/10.5439/1150245).

Supplement. The supplement related to this article is available online at: https://doi.org/10.5194/gmd-12-1833-2019-supplement.

Author contributions. DC, JH, and FDA designed the research, contributed to data processing and analysis, and wrote the original paper. PWR, PM, YYS, and MHA contributed to the investigation in Sect. 2. LL, CR, and FSM contributed with the curation of observed data. FDP, DG, SG, FR, EIR, and ErR contributed with software development. AC, EG, SL, SN, and MV contributed to validation data analysis. All coauthors helped to revise the paper.

Competing interests. The authors declare that they have no conflict of interest.

Acknowledgements. This work has been stimulated through COST Actions supported by COST (European Cooperation in Science and Technology). Support from the European Space Agency through the WRad project (ESA contract no. 4000125141/18/NL/AF) is acknowledged. Part of this research was funded by the Korea Meteorological Administration Research and Development Program under grant KMI2018-07410. Microwave radiometer and radiosonde data in Lamont (OK, USA) were obtained from the Atmospheric Radiation Measurement (ARM) User Facility, a U.S. Department of Energy (DOE) Office of Science user facility managed by the Office of Biological and Environmental Research.

Review statement. This paper was edited by Klaus Gierens and reviewed by two anonymous referees.

\section{References}

Atmospheric Radiation Measurement (ARM): user facility 2006, updated daily, Microwave Radiometer - High Frequency (MWRHFCAL150), 2012-01-01 to 2012-02-29, Southern Great Plains (SGP) Central Facility, Lamont, OK (C1), compiled by: Cadeddu, M. and Ghate, V., ARM Data Center, https://doi.org/10.5439/1150245, 2018a.

Atmospheric Radiation Measurement (ARM): user facility 1994, updated daily, Balloon-borne sounding system (SONDEWNPN), 2012-01-01 to 2012-02-29, Southern Great Plains (SGP) Central Facility, Lamont, OK (C1), compiled by: Coulter, R., Prell, J., Ritsche, M., and Holdridge, D., ARM Data Center, https://doi.org/10.5439/1150245, 2018 b.

Cadeddu, M. P., Liljegren, J. C., and Turner, D. D.: The Atmospheric radiation measurement (ARM) program network of microwave radiometers: instrumentation, data, and retrievals, Atmos. Meas. Tech., 6, 2359-2372, https://doi.org/10.5194/amt-62359-2013, 2013.
Cimini, D.: RTTOV-gb, available at: http://cetemps.aquila.infn.it/ rttovgb/rttovgb.html, last access: 29 April 2019.

Cimini, D., Westwater, E. R., Gasiewski, A. J., Klein, M., Leusky, V., and Liljegren, J.: Ground-based millimeter- and submillimiter-wave observations of low vapor and liquid water contents, IEEE T. Geosci. Remote, 45, 2169-2180, https://doi.org/10.1109/TGRS.2007.897450, 2007.

Cimini, D., Rosenkranz, P. W., Tretyakov, M. Y., Koshelev, M. A., and Romano, F.: Uncertainty of atmospheric microwave absorption model: impact on ground-based radiometer simulations and retrievals, Atmos. Chem. Phys., 18, 15231-15259, https://doi.org/10.5194/acp-18-15231-2018, 2018.

Clough, S. A., Shephard, M. W., Mlawer, E. J., Delamere, J. S., Iacono, M. J., Cady-Pereira, K., Boukabara, S., and Brown, P. D.: Atmospheric radiative transfer modeling: a summary of the AER codes, J. Quant. Spectrosc. Ra., 9, 233-244, 2005.

De Angelis, F., Cimini, D., Hocking, J., Martinet, P., and Kneifel, S.: RTTOV-gb - adapting the fast radiative transfer model RTTOV for the assimilation of ground-based microwave radiometer observations, Geosci. Model Dev., 9, 2721-2739, https://doi.org/10.5194/gmd-9-2721-2016, 2016.

De Angelis, F., Cimini, D., Löhnert, U., Caumont, O., Haefele, A., Pospichal, B., Martinet, P., Navas-Guzmán, F., Klein-Baltink, H., Dupont, J.-C., and Hocking, J.: Long-term observations minus background monitoring of ground-based brightness temperatures from a microwave radiometer network, Atmos. Meas. Tech., 10, 3947-3961, https://doi.org/10.5194/amt-10-3947-2017, 2017.

Eyre, J. R.: A fast radiative transfer model for satellite sounding systems, ECMWF Research Dept. Tech. Memo. 176, available at: https://www.ecmwf.int/file/22131/download? token=8Z5Jws9c (last access: 27 April 2019), 1991.

Hocking, J. and Rundle, D.: RTTOV v11 web page, available at: http://nwpsaf.eu/site/software/rttov/rttov-v11/, last access: 29 April 2019

Hocking, J., Rayer, P., Saunders, R., Madricardi, M., Geer, A., Brunel, P., and Vidot, J.: RTTOV v11 Users Guide, Doc ID: NWPSAF-MO-UD-028, available at: https://www.nwpsaf.eu/site/download/documentation/rtm/docs_ rttov11/users_guide_11_v1.4.pdf (last access: 14 November 2018), 2015.

Illingworth, A. J., Cimini, D., Gaffard, C., Haeffelin, M., Lehmann, V., Löhnert, U., O'Connor, E., and Ruffieux, D.: Exploiting Existing Ground-Based Remote Sensing Networks To Improve High Resolution Weather Forecasts, B. Am. Meteorol. Soc., 2015, 2107-2125, https://doi.org/10.1175/BAMS-D-13$00283.1,2015$.

Illingworth, A. J., Cimini, D., Haefele, A., Haeffelin, M., Hervo, M., Kotthaus, S., Löhnert, U., Martinet, P., Mattis, I., O'Connor, E. J., and Potthast, R.: How can Existing Ground-Based Profiling Instruments Improve European Weather Forecasts?, B. Am. Meteorol. Soc., https://doi.org/10.1175/BAMS-D-17-0231.1, in press, 2019.

Joint Committee for Guides in Metrology (JCGM): Evaluation of Measurement Data - Guide to the Expression of Uncertainty in Measurement, available at: https://www.bipm.org/utils/common/ documents/jcgm/JCGM_100_2008_E.pdf (last access: 25 May 2018), 2008.

Liebe, H. J.: MPM - An atmospheric millimeter wave propagation model, Int. J. Infrared Milli., 10, 631-650, 1989. 
Liljegren, J. C., Boukabara, S. A., Cady-Pereira, K., and Clough, S. A.: The effect of the half-width of the $22-\mathrm{GHz}$ water vapor line on retrievals of temperature and water vapor profiles with a twelve-channel microwave radiometer, IEEE T. Geosci. Remote, 43, 1102-1108, https://doi.org/10.1109/TGRS.2004.839593, 2005.

National Research Council: Committee on Developing Mesoscale Meteorological Observational Capabilities to Meet Multiple Needs, Observing Weather and Climate from the Ground Up: A Nationwide Network of Networks, ISBN: 978-0-309-129862, 250 pp., 2008.

Navas-Guzmán, F., Kämpfer, N., Schranz, F., Steinbrecht, W., and Haefele, A.: Intercomparison of stratospheric temperature profiles from a ground-based microwave radiometer with other techniques, Atmos. Chem. Phys., 17, 14085-14104, https://doi.org/10.5194/acp-17-14085-2017, 2017.

NWP SAF: Numerical Weather Prediction, Supporting the use of satellite data for NWP, available at: https://www.nwpsaf.eu/site/, last access: 14 November 2018.

Payne, V. H., Delamere, J. S., Cady-Pereira, K. E., Gamache, R. R., Moncet, J.-L., Mlawer, E. J., and Clough, S. A.: Air-broadened half-widths of the 22 and $183 \mathrm{GHz}$ water vapor lines, IEEE T. Geosci. Remote, 46, 3601-3617, 2008.

Riva, C., Capsoni, C., Luini, L., Luccini, M., Nebuloni, R., and Martellucci, A.: The challenge of using the $\mathrm{W}$ band in satellite communication, Int. J. Satell. Comm. N., 32, 187-200, https://doi.org/10.1002/sat.1050, 2014.

Rosenkranz, P. W.: Water vapor microwave continuum absorption: A comparison of measurements and models, Radio Sci., 33, 919 928, https://doi.org/10.1029/98RS01182, 1998.

Rosenkranz, P. W.: Line-by-line microwave radiative transfer (non-scattering), Remote Senssing Code Library, https://doi.org/10.21982/M81013, 2017.

Rundle, D.: NWP SAF profile datasets, web page, available at: https://nwpsaf.eu/deliverables/rtm/profile_datasets.html, last access: 29 April 2019.
Saunders, R., Hocking, J., Rundle, D., Rayer, P., Havemann, S., Matricardi, M., Geer, A., Lupu, C., Brunel, P., and Vidot, J.: RTTOV-12 Science and validation report, Doc ID: NWPSAF-MO-TV-41, Version 1.0, 16 February 2017, available at: https://www.nwpsaf.eu/site/download/documentation/ rtm/docs_rttov12/rttov12_svr.pdf (last access: 11 January 2018), 2017.

Saunders, R., Hocking, J., Turner, E., Rayer, P., Rundle, D., Brunel, P., Vidot, J., Roquet, P., Matricardi, M., Geer, A., Bormann, N., and Lupu, C.: An update on the RTTOV fast radiative transfer model (currently at version 12), Geosci. Model Dev., 11, 27172737, https://doi.org/10.5194/gmd-11-2717-2018, 2018.

Stähli, O., Murk, A., Kämpfer, N., Mätzler, C., and Eriksson, P.: Microwave radiometer to retrieve temperature profiles from the surface to the stratopause, Atmos. Meas. Tech., 6, 2477-2494, https://doi.org/10.5194/amt-6-2477-2013, 2013.

Tretyakov, M. Yu., Koshelev, M. A., Dorovskikh, V. V., Makarov, D. S., and Rosenkranz, P. W.: $60 \mathrm{GHz}$ oxygen band: precise broadening and central frequencies of fine structure lines, absolute absorption profile at atmospheric pressure, and revision of mixing coefficients, J. Mol. Spectrosc., 231, 1-14, https://doi.org/10.1016/j.jms.2004.11.011, 2005.

Turner, D. D., Clough, S. A., Liljegren, J. C., Clothiaux, E. E., Cady-Pereira, K. E., and Gaustad, K. L.: Retrieving liquid water path and precipitable water vapor from the Atmospheric Radiation Measurement (ARM) microwave radiometers, IEEE T. Geosci. Remote, 45, 3680-3690, https://doi.org/10.1109/TGRS.2007.903703, 2007.

Turner, E., Rayer, P., and Saunders, R.: AMSUTRAN: A microwave transmittance code for satellite remote sensing, J. Quant. Spectrosc. Ra., 227, 117-129, https://doi.org/10.1016/j.jqsrt.2019.02.013, 2019. 